\title{
Tuberculous meningitis due to Mycobacterium bovis: a report of two cases
}

\author{
E.G.L. Wilkins ${ }^{1}$, R.J. Griffiths ${ }^{1}$, C. Roberts ${ }^{1}$ and H.T. Green ${ }^{2}$ \\ ${ }^{1}$ Public Health Laboratory, Fazakerley Hospital, Liverpool, L9 7 AL and ${ }^{2}$ Bacteriology Laboratory, Walton \\ Hospital, Liverpool L9 1AE, UK.
}

\begin{abstract}
Summary: Two Caucasian patients with bovine tuberculous meningitis are described. Classical Mycobacterium bovis was isolated from the cerebrospinal fluid on both occasions. Despite the elimination of cattle tuberculosis in this country, reactivated primary disease due to the bovine tubercle bacillus may still occur.
\end{abstract}

\section{Introduction}

Tuberculosis of the central nervous system can occur in three forms: meningitic (the commonest), tuberculomatous, or as disseminated miliary encephalitis (Grange, 1980). Early this century tuberculous meningitis showed a predilection for the young and one quarter of all cases resulted from bovine infections (Griffiths, 1930). More recently, reports of classical Mycobacterium bovis causing tuberculous meningitis have been exceptionally rare and in six reviews in the United Kingdom since 1979 totalling 152 cases, only one bovine infection was encountered (Naughten et al., 1981; Swart et al., 1981; Traub et al., 1984; Bateman et al., 1983; Kennedy \& Fallon, 1979; Dixon et al., 1984). Disease in adults or the elderly has also become more common and may present in clinical guises outside that of 'classical' meningitis (Dixon et al., 1984). In this report we describe two cases of tuberculous meningitis in adults caused by $M$. bovis and review the changing nature of the disease.

\section{Case reports}

\section{Case 1}

A 50 year old Caucasian man in good general health underwent standard hip replacement surgery for Perthe's disease. Post-operatively he developed an inter-

Correspondence: C. Roberts, B.Sc., M.D., F.R.C.Path., Dip.Bact.

Accepted: 3 January 1986 mittent pyrexia which was initially ascribed to wound infection and left calf deep vein thrombosis. However, the fever persisted despite adequate treatment of these complications and his general condition deteriorated. Three months post-operatively he suffered a right sided focal fit followed by loss of consciousness and was transferred to the Regional Neurology Centre. The only notable feature in his past medical history was probable tuberculosis in childhood. On examination he was extremely ill, pyrexial, disorientated, with generalized hyperreflexia and an equivocal left plantar response. A computed tomographic (CT) scan was normal and there was no evidence of raised intracranial pressure but lumbar puncture revealed clear fluid with a white cell count of $23 \times 10^{6} / 1$ (all neutrophils), protein of $0.55 \mathrm{~g} / 1$ and glucose of $1.2 \mathrm{mmol} / 1$ (blood glucose $5.1 \mathrm{mmol} / \mathrm{l})$. Bacteria were not seen on cerebrospinal fluid (CSF) smear or culture, and acidfast bacilli (AFB) were not seen. The initial chest X-ray showed miliary mottling but sputum smears for AFB were negative. The differential diagnosis included partially treated pyogenic meningitis, miliary tuberculosis with tuberculous meningitis and disseminated candidiasis. The patient received courses of antibacterial therapy (chloramphenicol, benzyl penicillin and metronidazole), antituberculous therapy (rifampicin and isoniazid) and miconazole. However, he deteriorated further, developing severe hypotension and pulmonary oedema and died one month later. The findings at post-mortem examination were of overwhelming tuberculosis involving all organs including the brain, meninges and adrenal glands. Subsequently $M$. bovis was cultivated from sputum and CSF samples as well as specimens taken at post-mortem. The 
organism was resistant to pyrazinamide but otherwise was sensitive to all the standard antituberculous drugs.

\section{Case 2}

A 53 year old previously fit Caucasian woman with no past history or recent contact with tuberculosis presented with generalized weakness, increasing drowsiness, anorexia and weight loss of four months duration. In the $\mathbf{1 0}$ days preceding admission her general condition had worsened and on examination she was emaciated, drowsy, with signs of meningitis. There was no evidence of raised intracranial pressure nor any localizing neurological features. A chest X-ray showed diffuse mottling. A lumbar puncture yielded straw coloured fluid with a white cell count of $5 \times 10^{6} / 1$, protein of $1.4 \mathrm{~g} / 1$, and glucose of $3.5 \mathrm{mmol} / 1$. Microscopy showed one acid-fast bacillus and subsequently $M$. bovis was cultured. The patient was treated with triple antituberculous therapy and, apart from transient left sided upper motor neurone signs, made a slow and uncomplicated recovery. The organism was resistant to pyrazinamide but sensitive to all the other commonly used antituberculous agents.

\section{Discussion}

It was Green in 1836 who first introduced the term tubercular meningitis and distinguished this disease from the other central nervous system disorders of children. Its incidence in a given community parallels that of tuberculous infection in general and it therefore remains a common problem in the developing world, although the disease is now infrequently encountered in industrialized countries. Nevertheless, several recent reports from the United Kingdom attest to the continued presence of tuberculous meningitis, to the changing pattern of the disease, and to the importance of maintaining a high index of suspicion in its diagnosis (Naughten et al., 1981; Swart et al., 1981; Traub et al., 1984; Bateman et al., 1983; Kennedy \& Fallon, 1979; Dixon et al., 1984). Textbook cases still occur but the clinical presentation has become increasingly varied especially as more cases in the elderly are described. Associated tuberculous lesions outside the central nervous system appear to have become less common (Kocen, 1977) and more bacteriologically confirmed cases with atypical cerebrospinal fluid findings are being reported (Swart et al., 1981; Bateman et al., 1983; Kennedy \& Fallon, 1979). The two cases presented in this report exemplify many of these aspects and do not conform to the so-called 'classical' picture of tuberculous meningitis. Of special interest is the finding of a normal CSF white cell count in one patient and a neutrophilic response in the other, both being recognized but rare features of tuberculous meningitis (Kennedy \& Fallon, 1979).

Before the systematic testing and destruction of tuberculin positive cattle (the Attested Herds Scheme; completed in England \& Wales in 1960), one quarter of all tuberculous meningitis cases resulted from $M$. bovis infections (Griffiths, 1930). Since 1960, however, the possibility that the public could contract the disease directly or indirectly from cattle has been virtually non-existent and consequently the isolation rate for classical $M$. bovis from all sites has fallen. By correlating the prevalences of tuberculous infection in cattle and tuberculin reactors in school children, it has been concluded that in many rural districts the majority of reactors born before 1950 have been sensitized with bovine tubercle bacilli (Lesslie et al., 1972). Therefore, this implies a sizeable reservoir of dormant viable $M$. bovis bacilli still exists in adults which, as in the two patients presented, can later reactivate.

Cases of CSF culture-positive $M$. bovis meningitis have become rare. As far as we can ascertain, there have been only three published cases from Western countries of intracranial $M$. bovis infection in the last decade and in only one of these was the spinal fluid culture-positive (Traub et al., 1984; Jones \& Silva, 1982; Heath \& Grant, 1984). In England and Wales from 1975 to 1981 inclusive, only eight CSF isolates of $M$. bovis were reported to Central Diseases Surveillance Centre and even this may include cases of $M$. africanum infection which, because of its close laboratory resemblance to $M$. bovis, is often reported as such (Collins \& Grange, 1983). Differentiation is based upon testing for pyrazinamide susceptibility (classical $M$. bovis is resistant) and is usually confined to specialized centres. The identification of bovine tubercle bacilli in tuberculous meningitis is not just a matter of historical and epidemiological interest because the excellent penetration of pyrazinamide into the CSF and its unique intracellular activity combine to make it a recommended first line drug in treatment (Forgan-Smith et al., 1973). Its impotence in M. bovis infection because of the organism's natural resistance means that another bactericidal drug should be used instead.

These two cases are a reminder of the varied clinical presentations of tuberculous meningitis, the not infrequent absence of typical CSF findings, and the persistent reservoir of bovine tubercle bacilli that exists in the adult population which occasionally may reactivate.

\section{Acknowledgements}

We are grateful to Dr I.R. Williams, Walton Hospital and Dr W.B. Hanley, Southport General Infirmary, for permission to report these 2 cases. We also thank Miss Karen Whalley for secretarial help. 


\section{References}

BATEMAN, D.E., NEWMAN, P.K. \& FOSTER, J.B. (1983). A retrospective survey of proven cases of tuberculous meningitis in the Northern region, 1970-1980. Journal of the Royal College of Physicians, 17, 106.

COLLINS, C.H. \& GRANGE, J.M. (1983). The bovine tubercle bacillus. Journal of Applied Bacteriology, 55, 13.

DIXON, P.E., HOEY, C. \& CAYLEY, A.C.D. (1984). Tuberculous meningitis in the elderly. Postgraduate Medical Journal, 60, 586.

FORGAN-SMITH, R., ELLARD, G.A., NEWTON, D. \& MITCHISON, D.A. (1973). Pyrazinamide and other drugs in tuberculous meningitis. Lancet, ii, 374.

GRANGE, J.M. (1980). Mycobacterial diseases. In Current Topics in Infection Series, no. 1, Phillips, I. (ed). Edward Arnold: Bath.

GREEN, P.H. (1836). Tubercular meningitis. Lancet, ii, 232.

GRIFFITHS, A.S. (1930). Bacillus tuberculosis. In A System of Bacteriology in Relation to Medicine. HMSO: London.

HEATH, P.D. \& GRANT, J.W. (1984). Intracranial infection due to Mycobacterium bovis in Hodgkin's disease. British Medical Journal, 288, 465.

JONES, P.G. \& SILVA, J. (1982). Mycobacterium bovis menin- gitis. Journal of the American Medical Association, 247, 2270.

KENNEDY, D.H. \& FALLON, R.J. (1979). Tuberculous meningitis. Journal of the American Medical Association, 241, 264.

KOCEN, R.S. (1977). Tuberculous meningitis. British Journal of Hospital Medicine, 18, 436.

LESSLIE, I.W., MAGNUS, K. \& STEWART, C.J. (1972). The prevalence of bovine type tuberculosis infection in man in the English rural population. Tubercle, 53, 198.

NAUGHTEN, E., NEWTON, R., WEINDLING, A.M. \& BOWER, B.D. (1981). Tuberculous meningitis in children. Lancet, ii, 973.

REPORT TO THE MEDICAL RESEARCH COUNCIL (1949). Non-pulmonary tuberculosis in England and in Wales 1943-1945. Journal of Hygiene (Cambridge), 47, 337.

SWART, S., GRIGGS, R.S. \& MILLIR, P.A. (1981). Tuberculous meningitis in Asian patients. Lancet, ii, 15.

TRAUB, M., COLCHESTER, A.C.F., KINGSLEY, D.F.E. \& SWASH, M. (1984). Tuberculosis of the central nervous system. Quarterly Journal of Medicine, 209, 81. 